\title{
ANALISIS PENGOLAHAN AIR TERPRODUKSI DI WATER TREATING PLANT PERUSAHAAN EKSPLOITASI MINYAK BUMI (STUDI KASUS: PT XYZ)
}

\author{
Pertiwi Andarani*, Arya Rezagama \\ Program Studi Teknik Lingkungan \\ Fakultas Teknik UNDIP, JI. Prof H. Sudarto SH Tembalang Semarang \\ *Email: andarani@gmail.com
}

\begin{abstract}
The exploration and production process of oil and its supporting operations always generates waste as by-product. If they are uncontrolled, it might decrease the environmental quality. Thus, it is necessary to manage and treat the waste in order to meet the regulation standard of quality and quantity. $P T X Y Z$ is an energy company, particularly oil and gas production, which its production activity generate a large amount of waste as well as produced water. Thus, PT XYZ must have facilities or produced water handling plant which could minimize pollution caused by produced water. PT XYZ already has a system of produced water handling with recycling principle. After oil and water separation including water treating at Water Treating Plant (WTP), produced water will be used for steam injection. This is the part of enhanced oil recovery by steam flooding in Duri Field. Besides, produced water could be used as backwash water at WTP, that is Oil Removal Filter (ORF) and Water Softener, which is called brine water. If the produced water and brine water is over load the capacity of oil enhanced recovery injection, it might be disposed through injection to Disposal Well and there are certain condition that produced water should be discharged into canal. The objective $f$ this study is to analyze the performance of a water treating plant in PT XYZ. Water Treating Plant is a facility for treating produced water. Basically, WTP is on good condition and each unit has high efficiency for separating oil and water (60-99\%). Horizontal velocity at pit \#A of API Separator was larger than the design criteria. In addition, Water Softeners have efficiency until 99\% for the hardness.
\end{abstract}

Key words: produced water, Water Treating Plant, API Separator, oil removal filter, water softener

\section{PENDAHULUAN}

\section{Latar Belakang}

Minyak bumi terdapat dalam pori-pori yang berada di antara batuan-batuan sandstone dan limestone. Pori-pori ini memiliki ukuran yang beragam serta selain terdapat minyak, juga terdapat gas dan air yang ditemukan dalam suatu reservoir (Robinson, 2010). Oleh karena itu, dalam produksi minyak bumi dari suatu sumur minyak, gas dan air juga turut terproduksi. Apabila air terproduksi tersebut akan dibuang atau dialirkan ke suatu badan air penerima, tentunya karakteristik air tersebut harus dapat memenuhi baku mutu yang telah ditentukan. Karakteristik air terproduksi berbeda-beda sehingga setiap area dapat berbeda pula unit pengolahannya (Cakmaci dkk, 2008). Berdasarkan Arthur dkk (2005) dalam Fakhru'lRazi dkk, (2009), tujuan utama pengolahan air terproduksi adalah untuk (1) menyisihkan minyak dan lemak; (2) menyisihkan zat organik terlarut; (3) disinfeksi; (4) menyisihkan suspended solids; (5) menyisihkan gas terlarut; (6) desalinasi; (7) menurunkan kesadahan; (8) menyisihkan NORM (Naturally Occurring Radioactive Materials).
Volume air terproduksi akan semakin meningkat seiring dengan bertambahnya umur sungai (Judd dkk, 2014). Estimasi rasio antara air:minyak secara global adalah $~ 4: 1$ (TUV-NEL, 2010 dalam Judd dkk, 2014). Dengan persyaratan tertentu, air terproduksi dapat dibuang ke lingkungan yang berarti tidak diperoleh nilai dari adanya air terproduksi tersebut. Padahal, air terproduksi adalah limbah cair terbesar yang dihasilkan oleh industri minyak dan gas (Ahmadun dkk, 2009).

PT XYZ merupakan salah satu perusahaan energi yang utamanya mengeksploitasi minyak bumi di Pulau Sumatera, Indonesia (onshore). Mengingat salah satu landasan atau nilai yang dibangun oleh PT XYZ adalah melindungi manusia dan lingkungan dimana nilai ini telah ditempatkan pada proritas yang paling tinggi, diperlukan suatu usaha penanganan limbah secara terpadu dan bijaksana demi melindungi keberlanjutan lingkungan tersebut. Oleh karena itu, PT XYZ melakukan pengolahan terhadap air terproduksi tersebut untuk penginjeksian yang bertujuan untuk meningkatkan produksi minyaknya melalui injection well. Dalam hal ini, prinsip recycle selalu diterapkan seefesien mungkin. Metode yang digunakan dalam 
pengelolaan yang dilakukan untuk limbah cair ini adalah metode injeksi melalui Disposal Well. Metode injeksi mengacu pada Peraturan Menteri Lingkungan Hidup Nomor 13 tahun 2007 tentang Persyaratan dan Tata Cara Pengelolaan Air Limbah Bagi Usaha dan/atau Kegiatan Hulu Minyak dan Gas serta Panas Bumi dengan Cara Injeksi dan sebagai baku mutu effluen limbah cair kegiatan minyak dan gas adalah Peraturan Menteri Lingkungan Hidup Nomor 4 tahun 2007 tentang Baku Mutu Air Limbah Bagi Usaha dan/atau Kegiatan Minyak dan Gas serta Panas Bumi. Dengan penerapan teknologi injeksi ini diharapkan akan tercapai zero water discharge.

\section{Sistem Pengolahan Air Terproduksi}

Dalam pengeboran minyak bumi, tidak hanya dihasilkan fluida yang mengandung minyak saja, tetapi juga air, emulsi, gas, dan lumpur. Minyak yang merupakan hasil yang diharapkan hanya terkandung sebesar $\pm 15 \%$ dari total fluida yang disisihkan dari sistem pengolahan minyak tersebut akan dialirkan ke WTP untuk dapat dimurnikan kembali. Air hasil pengolahan akan digunakan sebagai steam injection (yang dimanfaatkan untuk dapat meningkatkan hasil produksi) dan apabila masih ada kelebihan air yang terproduksi akan dialirkan ke badan air penerima (kanal). Untuk lebih jelasnya, diagram alir proses pengolahan air terproduksi dapat dilihat pada Gambar 1.

Water Treating Plant (WTP) terdiri dari 2 proses utama yaitu :

\section{Tahap Pembersihan Minyak (Deoiling)}

Tahap deoiling sangat dipengaruhi oleh faktorfaktor seperti waktu, guncangan, dan bahan kimia yang digunakan, sehingga dapat dikatakan bahwa tahap deoiling merupakan fungsi dari faktor-faktor tersebut. Waktu yang cukup memungkinkan minyak untuk terpisah dari campuran dan mengapung pada permukaan. Prinsip utama yang digunakan adalah

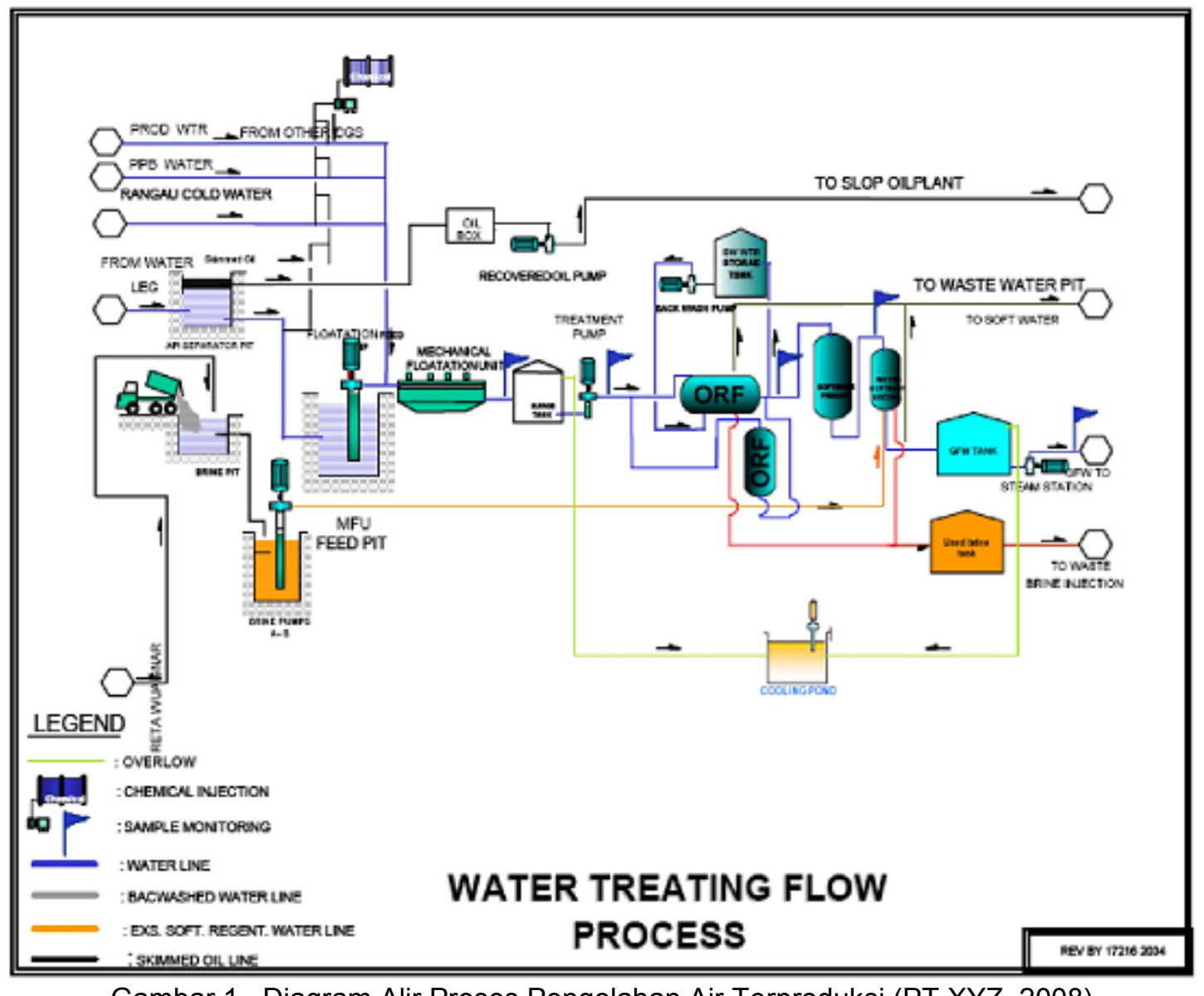

Gambar 1 Diagram Alir Proses Pengolahan Air Terproduksi (PT XYZ, 2008)

dihasilkan. Fungsi utama dari Water Treating Plant (WTP) adalah menyisihkan air yang terproduksi (produced water) yang datang dari sistem pengolahan utama yang menyisihkan gas dan minyak. Di PT XYZ ini, air yang telah menggunakan gravitasi. Melalui prinsip ini sekitar $75-80 \%$ minyak dapat dipisahkan. Oleh sebab itu konstruksi dari separator API (API Separator) dan pit sebagai media pertama yang menerima bahan baku air dirancang sedemikian rupa 
sehingga dapat memanfaatkan prinsip gravitasi untuk memisahkan minyak. Setelah itu, air mengalir dari pit tersebut menuju ke Mechanical Floatation Unit (MFU) lalu ORF (Oil Removal Filter).

\section{Tahap Pelunakkan / penurunan kesadahan (Softening)}

Pada tahap ini air akan mengalami proses pelunakkan sehingga mencapai tingkat kesadahan kurang dari $1 \mathrm{ppm}$ agar dapat digunakan sebagai air umpan pada steam generator yang akan ditampung dalam tangki Generated Feed Water (GFW)

Tujuan dari penelitian ini adalah untuk menganalisis kinerja unit pengolahan air terproduksi yang terdapat pada salah satu Water Treating Plant di PT XYZ.Penjelasan mengenai alat-alat yang digunakan pada proses pengolahan air meliputi :

\section{API Separator dan pompa}

Air yang berasal dari water leg akan dialirkan ke API Separator Pit / floatation pit. Pit adalah kolam yang didesain khusus untuk menampung air minyak dan solid atau padatan yang datang dari drain, Free Water Knocked Out (FWKO) tank, dan wash tank, limbah proses di WTP (back wash water ORF dan water softener, skimming MFU), limbah proses di Slope Oil Treating Plant atau dari sumber-sumber lainnya. Limbah-limbah tersebut ditampung dalam waste pit lalu dialirkan ke API Separator pit. Fluida yang mengalir ke dalam pit akan menjalani proses settling atau pengendapan secara gravitasi, sehingga dapat terpisah berdasarkan berat jenisnya. Padatanpadatan akan mengendap di dasar pit, air akan berada di tengah dan minyak mengapung di bagian atas. Secara berkala padatan akan diambil menggunakan excavator lalu diangkut dengan tailgate truck menuju ke Slurry Fracture Injection (SFI), air akan diproses lebih lanjut di WTP, dan minyak akan dipompakan ke Slope Oil Treating Plant. Pit dapat beroperasi secara tunggal ataupun gabungan antara beberapa sel. Pada sekat antara sel satu dengan yang lainnya, baffle atau siphon dirancang khusus sehingga memungkinkan hanya air yang dapat mengalir melalui baffle atau siphon menuju sel berikutnya, sedangkan sebagian besar padatan dan minyak akan tinggal di sel tersebut.

\section{Mechanical Floatation Unit (MFU)}

MFU adalah unit mekanis yang digunakan untuk memisahkan minyak dan padatan dari air kotor dengan cara agitasi, penginjeksian bahan kimia, dan udara sehingga minyak dan kotoran dapat terapung ke permukaan untuk diskim, ditampung, dan dialirkan ke pembuangan, sedangkan air yang keluar dari MFU dengan spesifikasi tertentu akan diolah ke proses berikutnya. Terdapat 4 buah sel pada MFU dan setiap sel diharapkan mampu menyisihkan $25 \%$ oil content (OC). Pada MFU ini dilakukan penambahan bahan kimia di bagian hulu (upstream) agar terbentuk floc. Air akan bergerak dari satu sel menuju ke sel lain melalui lubang yang terdapat di bawah baffle. Setiap sel dilengkapi dengan sebuah agitator yang digerakkan dengan motor listrik, agitator tersebut berfungsi untuk mengaduk air dan bahan kimia agar bercampur sempurna. Selanjutnya skimmer yang digerakkan oleh motor listrik akan membawa floc yang terapung di permukaan ke dalam oil box yang terdapat di sebelah kiri dan kanan sel MFU, kemudian dialirkan melalui pipa menuju waste pit. Air dari sel yang terakhir akan dialirkan ke surge tank melalui pipa keluar dari MFU. Pada pipa ini dipasang sebuah sample cock yang berfungsi untuk mengambil dan menguji sampel. Tujuan utama dari pengujian adalah untuk mengetahui kualitas air (terutama kandungan minyak) yang keluar dari masing-masing unit. Di samping itu, pengujian air juga berguna untuk menentukan jumlah bahan kimia yang akan diinjeksikan.

\section{Oil Removal Filter (ORF)}

ORF berfungsi sebagai media penyaringan terakhir dari air yang masih mengandung minyak dan kotoran dari MFU sebelum air tersebut dialirkan menuju proses softening di water softener. Hal ini disebabkan resin yang terdapat dalam water softener memiliki daya tarik yang tinggi dengan minyak sehingga kandungan minyak yang terdapat dalam air dapat menurunkan efisiensi dari softener tersebut. Faktor lain yang dapat menurunkan efisiensi dari softener adalah peningkatan penggunaan banyaknya garam, pengurangan kapasitas softener, dan memperpendek waktu pelayanan (service time) dari softener. Filter yang digunakan terdiri dari 2 jenis filter yaitu Horizontal dan Vertikal Multimedia. Media yang digunakan pada ORF Horizontal adalah pasir, yaitu garnet dan antrasit; sedangkan media yang digunakan pada ORF Vertikal adalah kacang-kacangan, yaitu pecan shell dan walnut.

\section{Water Softener}

Air terproduksi memiliki tingkat kesadahan yang tinggi. Kesadahan ini dapat mengganggu proses selanjutnya karena kesadahan dapat menyebabkan terbentuknya scale/kerak dalam pipa dan alat pemanas. Kesadahan paling banyak disebabkan oleh adanya ion $\mathrm{Ca}^{2+}$ dan $\mathrm{Mg}^{2+}$. Water Softener ini berfungsi untuk menurunkan kesadahan tersebut dengan cara penukaran ion. Media yang digunakan adalah Na-Zeolit. Penukar ion akan menyisihkan ion kalsium dan ion magnesium dari air dengan cara 
menggantikan mereka dengan ion sodium. Kalsium dan magnesium tersebut (dan sedikit ion $\mathrm{Fe}$ ) membuat air menjadi sadah. Softener akan meningkatkan TDS (Total Dissolved Solid) dari air yang telah lunak.

\section{METODE}

\section{Perhitungan Efisiensi API Separator}

Untuk mengetahui kinerja operasi pit, maka kondisi aktual akan dibandingkan dengan kriteria desain yang tercantum pada Tabel 1 .

Data setiap parameter pada kondisi aktual diambil setiap bulan dan diambil rata-ratanya.

Kecepatan horizontal dapat dihitung dengan persamaan:

$\mathrm{V}_{\mathrm{H}}=\mathrm{Q} / \mathrm{A}_{\text {cross }}=\mathrm{Q} /(\mathrm{I} \mathrm{x} \mathrm{d})$

dimana

$Q$ : debit $\left(\mathrm{m}^{3} / \mathrm{mnt}\right)\left(1\right.$ BWPD $\left.=0,00011 \mathrm{~m}^{3} / \mathrm{mnt}\right)$;

I : lebar pit $(\mathrm{m})$; $d$ : kedalaman $(\mathrm{m})$;

$\mathrm{V}_{\mathrm{H}}$ : kecepatan horizontal $(\mathrm{m} / \mathrm{mnt})$
Uniit pengolahan yang akan dianalisis efisiensinya adalah Mechanical Floatation Unit (MFU), Oil Removal Filter (ORF), dan Water Softener. Efisiensi dari suatu unit pengolahan dapat diperoleh dari Persamaan:

$$
\begin{aligned}
& \eta(\%)=\frac{\text { Cinlet }- \text { Coutlet }}{\text { Cinlet }} \times 100 \% \\
& \text { dimana } \\
& \eta \quad: \text { efisiensi (\%); } \\
& \mathrm{C}_{\text {inlet }} \quad: \text { konsentrasi di inlet; } \\
& \mathrm{C}_{\text {outlet }} \quad: \text { konsentrasi di outlet }
\end{aligned}
$$

Untuk menghitung konsentrasi inlet, dapat

\begin{tabular}{|c|c|c|}
\hline \multirow{2}{*}{ Parameter Desain } & \multicolumn{2}{|c|}{ Debit Desain } \\
\hline & $<185 \operatorname{gpm}(11,7$ L/s) & $>185 \operatorname{gpm}(11,7 \mathrm{~L} / \mathrm{s})$ \\
\hline $\begin{array}{l}{ }^{1} \text { Maksimum Surface Loading, gpd } / \mathrm{ft}^{2} \\
\left(\mathrm{~L} / \mathrm{s}-\mathrm{m}^{2}\right)\end{array}$ & $\begin{array}{l}{ }^{2} 1,000 \text { to } 2,000 \\
(11,3 \text { to } 22,6)\end{array}$ & $1,000(11,3)$ \\
\hline Panjang : Lebar (minimum) & $4: 1$ & $4: 1$ \\
\hline Kedalaman : Lebar & $1: 1$ (maksimum) & $0,3: 1$ to $0,5: 1$ \\
\hline${ }^{3}$ Maksimum Kedalaman, ft (m) & $3(0,9)$ & $5(1,5)$ \\
\hline $\begin{array}{l}\text { Maksimum Kecepatan Horizontal, } \\
\mathrm{fpm}(\mathrm{m} / \mathrm{mnt})\end{array}$ & $2(0,6)$ & $2(0,6)$ \\
\hline
\end{tabular}
digunakan data debit yang masuk ke WTP, yaitu air yang berasal dari API Separator, Waste Pit, PPB.

Tabel 1 Kriteria Desain API Separator

Sumber: Integrated Publishing, 2006

Keterangan:

1. Berdasarkan debit maksimum selama 24 jam

2. Digunakan nilai yang lebih rendah jika separator merupakan satu pengolahan. Digunakan nilai yang lebih tinggi jika separator merupakan pretreatment/komponen intermediate dari suatu sistem pengolahan.

Sedangkan, untuk beban permukaan (surface loading) dapat dihitung dengan Persamaan:

Beban permukaan $\left(\mathrm{L} / \mathrm{s}-\mathrm{m}^{2}\right)=\mathrm{Q} / \mathrm{A}_{\text {surface }}=\mathrm{Q} /(\mathrm{px}$ I) $\operatorname{dimana} Q$ : $\operatorname{debit}(\mathrm{L} / \mathrm{s}),\left(1 \mathrm{~m}^{3} / \mathrm{s}=1000 \mathrm{~L} / \mathrm{s}\right) ; \mathrm{p}$ : panjang pit $(\mathrm{m}) ; \mathrm{l}$ : lebar pit $(\mathrm{m})$

\section{Perhitungan Efisiensi Unit Pengolahan}

Pada Mechanical Floatation Unit (MFU) ini, akan dihitung efisiensi pengolahan, yaitu penyisihan kandungan minyak (OC, Oil content). Data setiap parameter yang dianalisis diambil setiap bulan dan diambil rata-ratanya.

$$
\begin{aligned}
& \text { Cinlet } O C=\frac{\left(\left(Q_{\text {pit A A }_{A}} \times O C\right)+\left(Q_{\text {pit } B} \times O C\right)+\left(Q_{\text {waste pit }} \times O C\right)+\left(Q_{P P B} \times O C\right)\right)}{Q_{\text {pit A A }}+Q_{\text {pit } B}+Q_{\text {waste pit }}+Q_{P P B}} \\
& \text { Cinlet Turb }=\frac{\left(\left(Q_{\text {pitzA }} \times \text { Turb }\right)+\left(Q_{\text {pit B }} \times \text { Turb }\right)+\left(Q_{\text {waste pit }} \times \text { Turb }\right)+\left(Q_{P P B} \times \text { Turb }\right)\right)}{Q_{\text {pit A A }}+Q_{\text {pits } B}+Q_{\text {waste pit }}+Q_{P P B}}
\end{aligned}
$$

\section{Dimana}

$\mathrm{C}_{\text {inlet OC }} \quad$ : konsentrasi OC di inlet (ppm);

$\mathrm{C}_{\text {inlet Turb }} \quad$ : konsentrasi Turb di inlet (NTU);

$Q_{\text {pit\#A }} \quad$ : debit inlet pit\#A (BWPD);

$Q_{\text {pit\#B }} \quad$ : debit inlet pit\#B (BWPD);

$\mathrm{Q}_{\text {waste pit }} \quad$ : debit inlet waste pit (BWPD);

$Q_{P P B} \quad$ : debit dari PPB (BWPD). 


\section{HASIL DAN PEMBAHASAN \\ API Separator}

API Separator dapat memisahkan partikel hidrokarbon berukuran lebih dari $150 \mu \mathrm{m}$ (Frankiewics, 2001 dalam Robinson, 2013). Diketahui bahwa API separator memiliki panjang 15 meter dan lebar 4 meter. Menurut kriteria desain, perbandingan $p: I=4: 1$, sehingga akan lebih tepat apabila API separator tersebut memiliki panjang 16 meter. Kedalaman yang dimiliki API Separator adalah 4 meter sehingga hal ini sesuai dengan kriteria desain API Separator dengan maksimum kedalaman 1,5 m ditambah penyimpanan volume minyak dan lumpur yang dibutuhkan. menyebabkan kecepatan horizontal menjadi melebihi kriteria desain $(0,6 \mathrm{~m} / \mathrm{mnt})$.

Contoh perhitungan (untuk No.1, pada Pit\#A) :

Beban permukaan $=609,307 \mathrm{~L} / \mathrm{s} /(15 \mathrm{~m} \times 4 \mathrm{~m})=$ $8,704 \mathrm{~L} / \mathrm{s}-\mathrm{m}^{2}$

Hasil perhitungan beban permukaan dapat dilihat pada Tabel 3.

Menurut kriteria desain, dengan debit $>11,7 \mathrm{~L} / \mathrm{s}$, beban permukaan maksimum adalah $11,3 \mathrm{~L} / \mathrm{s}-$ $\mathrm{m}^{2}$. Oleh karena itu, Pit \#A dan Pit \#B ini masih memenuhi kriteria desain dalam pengoperasiannya.

Tabel 2 Debit dan Kecepatan Horizontal pada API Separator

\begin{tabular}{|c|c|c|c|c|}
\hline \multirow{2}{*}{ No } & \multicolumn{2}{|c|}{ Pit \#A } & \multicolumn{2}{c|}{ Pit \#B } \\
\cline { 2 - 5 } & $\begin{array}{c}\mathbf{Q} \\
\left(\mathbf{m}^{\mathbf{3}} \mathbf{\text { mnt}}\right)\end{array}$ & $\begin{array}{c}\mathbf{V}_{\mathbf{H}} \\
(\mathbf{m} / \mathbf{m n t})\end{array}$ & $\begin{array}{c}\mathbf{Q} \\
\mathbf{( m}^{\mathbf{3}} / \mathbf{m n t}\end{array}$ & $\begin{array}{c}\mathbf{V}_{\mathbf{H}} \\
(\mathbf{m} / \mathbf{m n t})\end{array}$ \\
\hline I & 36,558 & 2,285 & 5,907 & 0,369 \\
\hline II & 36,901 & 2,306 & 5,892 & 0,368 \\
\hline III & 37,256 & 2,329 & 5,828 & 0,364 \\
\hline IV & 38,003 & 2,375 & 5,219 & 0,326 \\
\hline V & 37,240 & 2,328 & 5,394 & 0,337 \\
\hline VI & 37,362 & 2,335 & 5,313 & 0,332 \\
\hline
\end{tabular}

Tabel 3 Beban Permukaan (Surface Loading) API Separator

\begin{tabular}{|c|c|c|c|c|}
\hline \multirow{2}{*}{ No } & \multicolumn{2}{|c|}{ Pit \#A } & \multicolumn{2}{c|}{ Pit \#B } \\
\cline { 2 - 5 } & Debit (L/s) & $\begin{array}{c}\text { Surface Loading } \\
\left(\mathbf{L} / \mathbf{s}-\mathbf{m}^{2}\right)\end{array}$ & Debit (L/s) & $\begin{array}{c}\text { Surface Loading } \\
\left(\mathbf{L} / \mathbf{s}-\mathbf{m}^{2}\right)\end{array}$ \\
\hline I & 609,307 & 8,704 & 98,455 & 1,406 \\
\hline II & 615,008 & 8,786 & 98,199 & 1,403 \\
\hline III & 620,936 & 8,871 & 97,128 & 1,388 \\
\hline IV & 633,384 & 9,048 & 86,978 & 1,243 \\
\hline V & 620,669 & 8,867 & 89,901 & 1,284 \\
\hline VI & 622,698 & 8,896 & 88,556 & 1,265 \\
\hline
\end{tabular}

Contoh perhitungan (untuk No. I, pada Pit\#A :

$V_{H}=Q /(I \times d)=36,558 \mathrm{~m}^{3} / \mathrm{mnt} /(4 \mathrm{~m} \times 4 \mathrm{~m})=$ $2,285 \mathrm{~m} / \mathrm{mnt}$

Hasil perhitungan kecepatan horizontal dapat dilihat pada Tabel 2 .

Kecepatan horizontal pada Pit \#A terlalu besar sehingga memungkinkan pemisahan minyak secara gravitasi tidak berjalan dengan optimal, sedangkan pada Pit \#B masih memenuhi kriteria desain. Debit yang masuk pada Pit \#A cenderung jauh lebih besar daripada Pit \#B sehingga

\section{Mechanical Floatation Unit (MFU)}

Pada WTP-5, terdapat 5 unit MFU yang menerima air masukan dari API Separator, Waste Pit, PPB water. Jenis MFU yang digunakan adalah dispersed air flotation tipe rotor yang merupakan unit flotasi dimana digunakan gelembung gas yang secara mekanis terdispersi di dalam air akibat adanya rotor. Perputaran rotor menghasilkan vortex yang menyebabkan gas dan cairan berinteraksi di sepanjang rotor sampai dengan titik di daerah dasar kompartemen. 
Tabel 4 Konsentrasi OC dan Turbiditas di inlet MFU

\begin{tabular}{|c|c|c|c|c|c|c|c|c|c|c|c|c|c|c|}
\hline \multirow{3}{*}{ No } & \multicolumn{3}{|c|}{ PIT \#A } & \multicolumn{3}{|c|}{ PIT \#B } & \multicolumn{3}{|c|}{ Waste PIT } & \multicolumn{3}{|c|}{ PPB } & \multicolumn{2}{|c|}{$\begin{array}{c}\text { Konsentrasi } \\
\text { inlet }\end{array}$} \\
\hline & Debit & OC & Turb & Debit & OC & Turb & Debit & OC & Turb & Debit & OC & Turb & OC & Turb \\
\hline & (BWPD) & ppm & NTU & (BWPD) & ppm & NTU & (BWPD) & ppm & NTU & (BWPD) & ppm & NTU & ppm & NTU \\
\hline I & 331116,13 & 95,61 & 612,05 & 53503,23 & 171,41 & 391,90 & 60803,23 & 144,68 & 323,92 & 137806,13 & 14,66 & 17,77 & 88,55 & 421,40 \\
\hline II & 334214,29 & 91,43 & 357,69 & 53364,29 & 273,65 & 373,15 & 62332,14 & 116,94 & 134,13 & 135248,89 & 13,47 & 9,94 & 92,75 & 254,91 \\
\hline III & 337435,48 & 127,51 & 177,43 & 52782,26 & 436,24 & 579,19 & 63951,61 & 200,43 & 188,67 & 103769,23 & 26,23 & 7,22 & 146,24 & 185,07 \\
\hline IV & 344200,00 & 143,00 & 255,56 & 47266,67 & 609,91 & 1180,89 & 62433,33 & 270,58 & 195,49 & 117657,83 & 39,75 & 12,25 & 174,29 & 275,43 \\
\hline $\mathrm{V}$ & 337290,32 & 81,41 & 162,44 & 48854,84 & 301,22 & 577,22 & 64774,19 & 109,38 & 108,14 & 105298,48 & 14,19 & 9,98 & 91,25 & 163,69 \\
\hline VI & 338393,10 & 101,96 & 203,35 & 48124,14 & 247,71 & 262,79 & 62179,31 & 90,06 & 111,84 & 143653,31 & 24,69 & 9,28 & 93,81 & 151,51 \\
\hline
\end{tabular}

Tabel 5 Konsentrasi OC dan Turbiditas di outlet MFU

\begin{tabular}{|c|c|c|c|c|c|c|c|c|c|c|}
\hline \multirow{3}{*}{ No } & \multicolumn{2}{|c|}{ MFU \#A } & \multicolumn{2}{c|}{ MFU \#B } & \multicolumn{2}{c|}{ MFU \#C } & \multicolumn{2}{c|}{ MFU \#D } & \multicolumn{2}{c|}{ MFU \#E } \\
\cline { 2 - 12 } & OC & Turb & OC & Turb & OC & Turb & OC & NTU & OC & Turb \\
\cline { 2 - 12 } & $\mathbf{p p m}$ & NTU & $\mathbf{p p m}$ & NTU & $\mathbf{p p m}$ & NTU & ppm & NTU & ppm & NTU \\
\hline I & 3,37 & 9,04 & 3,52 & 9,32 & 3,47 & 9,90 & 3,56 & 9,37 & 2,52 & 6,44 \\
\hline II & 3,28 & 5,73 & 3,40 & 6,15 & 3,64 & 7,59 & 3,25 & 5,84 & 2,94 & 5,28 \\
\hline III & 3,75 & 9,44 & 3,84 & 6,51 & 3,84 & 7,08 & 2,90 & 4,10 & 2,52 & 3,27 \\
\hline IV & 5,70 & 9,27 & 3,72 & 7,24 & 3,61 & 8,38 & 3,30 & 5,29 & 2,46 & 4,25 \\
\hline V & 3,30 & 7,22 & 2,63 & 6,13 & 2,82 & 6,74 & 2,69 & 5,42 & 2,06 & 3,99 \\
\hline VI & 3,12 & 5,08 & 3,03 & 5,32 & 3,03 & 5,82 & 2,81 & 4,99 & 2,55 & 4,17 \\
\hline
\end{tabular}

Tabel 6 Efisiensi Penyisihan Oil Content dan Turbiditas di MFU

\begin{tabular}{|c|c|c|c|c|c|c|c|c|c|c|}
\hline \multirow{3}{*}{ No } & \multicolumn{2}{|c|}{ MFU \#A } & \multicolumn{2}{c|}{ MFU \# } & \multicolumn{2}{c|}{ MFU \#C } & \multicolumn{2}{c|}{ MFU \#D } & \multicolumn{2}{c|}{ MFU \#E } \\
\cline { 2 - 11 } & OC & Turb & OC & Turb & OC & Turb & OC & NTU & OC & Turb \\
\cline { 2 - 11 } & $\mathbf{p p m}$ & NTU & $\mathbf{p p m}$ & NTU & $\mathbf{p p m}$ & NTU & $\mathbf{p p m}$ & NTU & ppm & NTU \\
\hline \multirow{2}{*}{ I } & $96,19 \%$ & $97,86 \%$ & $96,02 \%$ & $97,79 \%$ & $96,08 \%$ & $97,65 \%$ & $95,97 \%$ & $97,78 \%$ & $97,16 \%$ & $98,47 \%$ \\
\hline II & $96,47 \%$ & $97,75 \%$ & $96,34 \%$ & $97,59 \%$ & $96,07 \%$ & $97,02 \%$ & $96,50 \%$ & $97,71 \%$ & $96,83 \%$ & $97,93 \%$ \\
\hline III & $97,44 \%$ & $94,90 \%$ & $97,38 \%$ & $96,48 \%$ & $97,38 \%$ & $96,18 \%$ & $98,02 \%$ & $97,78 \%$ & $98,28 \%$ & $98,23 \%$ \\
\hline IV & $96,73 \%$ & $96,63 \%$ & $97,87 \%$ & $97,37 \%$ & $97,93 \%$ & $96,96 \%$ & $98,10 \%$ & $98,08 \%$ & $98,59 \%$ & $98,46 \%$ \\
\hline V & $96,38 \%$ & $95,59 \%$ & $97,12 \%$ & $96,26 \%$ & $96,91 \%$ & $95,88 \%$ & $97,05 \%$ & $96,69 \%$ & $97,74 \%$ & $97,56 \%$ \\
\hline VI & $96,67 \%$ & $96,65 \%$ & $96,77 \%$ & $96,49 \%$ & $96,77 \%$ & $96,16 \%$ & $97,00 \%$ & $96,70 \%$ & $97,28 \%$ & $97,25 \%$ \\
\hline
\end{tabular}

Hasil perhitungan Cinlet dan Coutlet dapat dilihat pada Tabel 4 dan Tabel 5 secara berurutan.

Contoh perhitungan efisiensi (No. I, parameter OC pada MFU \#A) :

$$
\begin{aligned}
& \eta(\%)=\frac{\text { Cinlet }- \text { Coutlet }}{\text { Cinlet }} \times 100 \% \\
& \eta(\%)=\frac{88,55 \mathrm{ppm}-3,37 \mathrm{ppm}}{88,55 \mathrm{ppm}} \times 100 \% \\
& \eta(\%)=96,19 \%
\end{aligned}
$$

Hasil perhitungan efisiensi penyisihan $O C$ dan Turbiditas pada MFU dapat dilihat di Tabel 6.

Efisiensi penyisihan kandungan minyak dan turbiditas pada MFU di WTP sangat tinggi, yaitu berkisar $96 \%-98 \%$. Hal ini menunjukkan bahwa MFU tersebut masih efektif dalam menyisihkan kandungan minyak dan turbiditas.

\section{Oil Removal Filter (ORF)}

Pada WTP-5 terdapat 20 unit Oil Removal Filter (ORF). ORF ini merupakan intermediate treatment dalam sistem pengolahan air terproduksi. Efisiensi penyisihan kandungan 
minyak pada ORF adalah berkisar 90-95\% (Singh, 1976). Efisiensi penyisihan dapat dihitung dengan persamaan 6.4 dengan menggunakan data rata-rata dari 20 unit ORF.

Contoh perhitungan (No.I, parameter OC):

$$
\begin{aligned}
& \eta(\%)=\frac{\text { Cinlet }- \text { Coutlet }}{\text { Cinlet }} \times 100 \% \\
& \eta(\%)=\frac{3,54 \mathrm{ppm}-1,29 \mathrm{ppm}}{3,54 \mathrm{ppm}} \times 100 \% \\
& \eta(\%)=63,59 \%
\end{aligned}
$$

Rangkuman hasil perhitungan efisien penyisihan Oil Content dan Turbiditas dapat dilihat pada Tabel 7.

Menurut parameter operasi ORF dalam prosedur operasi standar, sebelum masuk ke filter kandungan minyak maksimal 5 ppm, sedangkan di outlet filter, kandungan minyak tersebut harus kurang dari $1 \mathrm{ppm}$. Dalam hal ini, terlihat bahwa ORF belum memenuhi standar tersebut. Hal ini kemungkinan dapat disebabkan oleh proses backwash yang kurang efektif atau media filter yang sebaiknya perlu diganti dengan media yang baru.

\section{Water Softener}

Kinerja operasi Softener pada saat evaluasi ini dapat dilihat pada Tabel 8. Dengan menggunakan data rata-rata dari 20 unit Softener, efisiensi dapat dihitung. Contoh perhitungan (No. 1, parameter Hardness):

$$
\begin{aligned}
& \eta(\%)=\frac{\text { Cinlet }- \text { Coutlet }}{\text { Cinlet }} \times 100 \% \\
& \eta(\%)=\frac{78,45 \mathrm{ppm}-0,62 \mathrm{ppm}}{78,45 \mathrm{ppm}} \times 100 \% \\
& \eta(\%)=99,20 \%
\end{aligned}
$$

Sesuai dengan tujuan pengolahan pada softener, penyisihan kesadahan (hardness) pada unit ini sangat tinggi, yaitu $98-99 \%$. Selain itu, apabila dibandingkan dengan parameter operasi, terlihat bahwa parameter Turbiditas dan Hardness telah memenuhi parameter operasi standard tersebut.

\begin{tabular}{|c|c|c|c|c|c|c|c|}
\hline \multirow{3}{*}{ No } & \multirow{3}{*}{$\begin{array}{c}\text { Debit } \\
\text { (BWPD) }\end{array}$} & \multicolumn{2}{|c|}{ Sebelum Filter } & \multicolumn{2}{|c|}{ Setelah Filter } & \multicolumn{2}{|c|}{ Efisiensi Penyisihan } \\
\hline & & OC & Turb & $\mathrm{OC}$ & Turb & $\mathrm{OC}$ & Turb \\
\hline & & ppm & NTU & ppm & NTU & ppm & NTU \\
\hline I & 30 & 3,54 & 10,50 & 1,29 & 4,41 & $63,59 \%$ & $57,99 \%$ \\
\hline II & 30 & 3,54 & 6,80 & 1,23 & 2,99 & $65,27 \%$ & $56,09 \%$ \\
\hline III & 32 & 3,82 & 6,53 & 1,35 & 2,68 & $64,79 \%$ & $58,90 \%$ \\
\hline IV & 31 & 3,89 & 8,59 & 1,53 & 4,52 & $60,65 \%$ & $47,39 \%$ \\
\hline $\mathrm{V}$ & 32 & 3,25 & 7,25 & 1,21 & 3,23 & $62,94 \%$ & $55,52 \%$ \\
\hline VI & 32 & 3,48 & 6,03 & 1,21 & 2,45 & $65,31 \%$ & $59,36 \%$ \\
\hline & & & & & rata-rata & $63,76 \%$ & $55,87 \%$ \\
\hline
\end{tabular}
Ketidaksesuaian terhadap parameter operas। terdapat pada inlet Softener, yaitu konsentrasi OC pada water inlet belum memenuhi persyaratan $(<1 \mathrm{ppm})$.

Tabel 7 Efisiensi Penyisihan ORF

Tabel 8 Efisiensi Penyisihan Oil Content, Turbiditas, dan Hardness pada Water Softener

\begin{tabular}{|c|c|c|c|c|c|c|c|c|c|}
\hline \multirow{2}{*}{ No } & \multicolumn{3}{|c|}{ Sebelum Softener } & \multicolumn{3}{c|}{ Setelah Softener } & \multicolumn{3}{c|}{ Efisiensi Penyisihan } \\
\cline { 2 - 10 } & OC & Turb & Hard & OC & Turb & Hard & OC & Turb & Hard \\
\cline { 2 - 10 } & $\mathbf{p p m}$ & NTU & $\mathbf{p p m}$ & $\mathbf{p p m}$ & $\mathbf{N T U}$ & $\mathbf{p p m}$ & $\mathbf{p p m}$ & NTU & ppm \\
\hline I & 1,29 & 4,41 & 78,45 & 0,79 & 3,04 & 0,62 & $38,92 \%$ & $31,04 \%$ & $99,20 \%$ \\
\hline II & 1,23 & 2,99 & 81,88 & 0,73 & 2,18 & 0,74 & $40,57 \%$ & $27,11 \%$ & $99,09 \%$ \\
\hline III & 1,35 & 2,68 & 81,35 & 0,75 & 1,66 & 0,85 & $44,31 \%$ & $38,11 \%$ & $98,96 \%$ \\
\hline IV & 1,53 & 4,52 & 87,49 & 0,78 & 2,09 & 0,86 & $49,24 \%$ & $53,78 \%$ & $99,02 \%$ \\
\hline V & 1,21 & 3,23 & 84,13 & 0,76 & 2,09 & 0,41 & $37,17 \%$ & $35,17 \%$ & $99,51 \%$ \\
\hline VI & 1,21 & 2,45 & 80,45 & 0,78 & 1,81 & 0,38 & $35,36 \%$ & $26,17 \%$ & $99,53 \%$ \\
\hline
\end{tabular}




\section{KESIMPULAN}

Proses pengolahan fluida produksi dimulai dari Oil Treating Plant yang terdiri dari pemisahan gas (gas boot) dari fluida produksi, pemisahan air (Free Water Knock Out Tank dan Wash Tank). Setelah itu, air akan diolah di Water Treating Plant yang terdiri dari proses deoiling (Floatation Pit, Mechanical Floatation Unit, Oil Removal Filter), dan proses penurunan kesadahan (softener). Berdasarkan hasil analisa, API Separator sudah memenuhi kriteria desain untuk beban permukaan (surface loading), tetapi untuk kecepatan horizontal pada pit\#A lebih tinggi dibandingkan dengan kriteria desain. Berdasarkan hasil perhitungan, efisiensi penyisihan OC pada MFU adalah berkisar 96$98 \%$, sedangkan turbiditas adalah berkisar 94$98 \%$. Efisiensi penyisihan OC pada ORF $60-65 \%$ (belum memenuhi standar operasi), penyisihan turbiditas $47-59 \%$. Efisiensi penyisihan kesadahan (hardness) pada softener mencapai $99 \%$.

\section{DAFTAR PUSTAKA}

Cakmaci, M., Kayaalp, N., Koyuncu, I. 2008. Desalination of produced water from oil production fields by membrane processes. Desalination, Vol. 222, HIm. 176-186.

Fakhru'l-Razi., Pendashteh, A., Abdullah, L.C., Biak, D.R.A., Madaeni, S.S., Abidin, Z.Z. 2009. Review of technologies for oil and gas produced water treatment. Journal of Hazardous Materials, VI. 170, HIm. 530551.

Integrated Publishing. 2006. "API Separator Design Criteria". <http://www.tpub.com/content/UFC2/ufc 4832 01n/ufc 4 8 832 01n0163.htm> $\overline{5}$ Jüli $20 \overline{15}$.

Judd, S., Qiblawey, H., Al-Marri, M., Clarkin, C., Watson, S., Ahmed, A., Bach, S. 2014. The size and performance of offshore produced water oil-removal technologies for injection. Separation and Purification Technology, Vol. 134, HIm. 241-246.

PT XYZ. 2008. Leaflet Oil Treating Plant dan Water Treating Plant.

Robinson, David. 2013. Oil and gas: Treatment and discharge of produced waters onshore. Filtration + Separation, Volume
50, Issue 3, May-June 2013, HIm. 40 46.

Robinson, David. 2010. Oil and gas: Water treatment in oil and gas production does it matter?. Filtration \& Separation, Volume 47, Issue 1, January-February 2010, HIm.14-18

Singh, Azad Hardam. 1976. Industrial Wastewater Management Handbook. McGraw-Hill Book Company. 